\title{
EVALUATION OF WELD HOMOGENIZATION SCHEMES BASED ON PLASTIC LOADING OF SINGLE EDGE NOTCHED TENSILE (SE(T)) TESTS
}

\author{
Sameera Naib \\ Soete Laboratory \\ Department of EEMMECS, \\ Ghent University, Belgium \\ sameera.naib@ugent.be
}

\author{
Wim De Waele \\ Soete Laboratory \\ Department of EEMMECS, \\ Ghent University, Belgium
}

\author{
Stijn Hertelé \\ Soete Laboratory \\ Department of EEMMECS, \\ Ghent University, Belgium
}

\begin{abstract}
Engineering Critical Assessment (ECA) of welds is the process of predicting the structural integrity of a structure in the presence of a weld defect under specified loading conditions. Standardized ECA techniques consider the weld to be equal in properties when compared with base metal or use the concept of 'strength mismatch' to distinguish the weld from the base metal. In both cases, the weld region is homogeneous. This is a severe approximation from reality, as welds show complex strength heterogeneity patterns. The authors are concerned with techniques to simplify welds in such way that the structural response of the weld is similar to that of the idealized, homogeneous weld. Two approaches are considered: (a) integrating properties along assumed slip lines originating from the defect tip, and (b) assigning All Weld Metal Tensile Tests (AWMTT) to the entire weld region. A plastic analysis procedure suggested by the ASME BP\&V code ('Twice Elastic Slope method') is adopted to estimate Plastic Load, whose values are compared for the heterogeneous and equivalent homogeneous welds. Finite Element (FE) simulations were performed for Single Edge notched Tensile (SE(T)) specimens. The results put forward the possibilities of weld homogenization while showing its limitations. This will assist in further improvement of weld ECA.
\end{abstract}

\section{INTRODUCTION}

Integrity assessment of mechanically loaded structures such as pipelines or pressure vessels, is a major requirement for safe operation, cost effective maintenance and lifetime estimation. A number of techniques are being used hereto. One of them is Engineering Critical Assessment (ECA). In order to perform an effective ECA, the location and size of the flaw, stress developed and toughness of the material around the flaw has to be identified. In the case of weldments, characterization of the weld region plays an important role to estimate the stresses and toughness around the flaw and consequently, the crack driving force.

Zerbst et al. [1] pointed out the challenge of predicting stresses and crack driving forces around the crack tip. They attribute the difficulty to the diversity in local microstructures which results in variations of constitutive properties within the weld region. These variations are due to the fluctuations in cooling rate after fusing or due to the succession of heating and cooling cycles occurring in multi-pass welds.

In the early 1990s, researchers used the term 'Mismatch' to characterize different sections of the weldment (base and weld region) based on their strength $[2,3]$. Mismatch is defined as the ratio of the flow strengths of weld and base material. This concept was extended to Heat Affected Zones (HAZ) and similar equations were formulated. Several standards and codes which are used for ECA, included the concept of mismatch by distinguishing between Base Material (BM), Weld Material (WM) and Heat Affected Zones (HAZ) [4-7]. These three different regions of weldment were categorized based on their constitutive properties. The local variations of strength are simplified and the weld region is considered to be a homogeneous body. This process of simplification is referred to 
as 'weld homogenization'. The complex fusion line profiles of butt welds are simplified as straight lines. This is termed as 'weld idealization'(Figure 1). Homogenization and idealization allow the safe assessment of a welded structure with less difficulty. On the other hand, it overlooks the presence of local variations in mechanical properties in the weld region requiring conservative safety factors and potentially making maintenance expensive.

To analyze weld characteristics, researchers and industries prevailingly use the material data from All Weld Metal Tensile Tests (AWMTT) to characterize the entire weld. Researchers [811] studied strength variations within the weld region using Vickers hardness mapping technique and showed that it is a robust technique to quantify weld heterogeneity. A new homogenization technique to simplify a complex weld using slip line analysis was formulated in [12].

In this paper, the structural responses of heterogeneous welds will be compared with those of their homogenized equivalents, obtained using AWMTT and slip line methods. A numerical Single Edge notched Tensile (SE(T)) model will be utilized. A detailed analysis of strain patterns developed around the notch is performed.

\section{MATERIAL AND METHODS}

\section{Weld Homogenization}

Two weld homogenization schemes were explored in this work. The detailed procedures of both the schemes are discussed below.

The most widely used technique to obtain weld constitutive properties is to extract an AWMTT specimen from a region of weld. The obtained stress-strain curve is assigned to the whole weld region. The process of weld idealization is performed as explained in Figure 1 and $2 H_{e q}$ is considered as the thickness of the weld. The assumed $45^{\circ}$ slip lines are considered up to the fusion line.

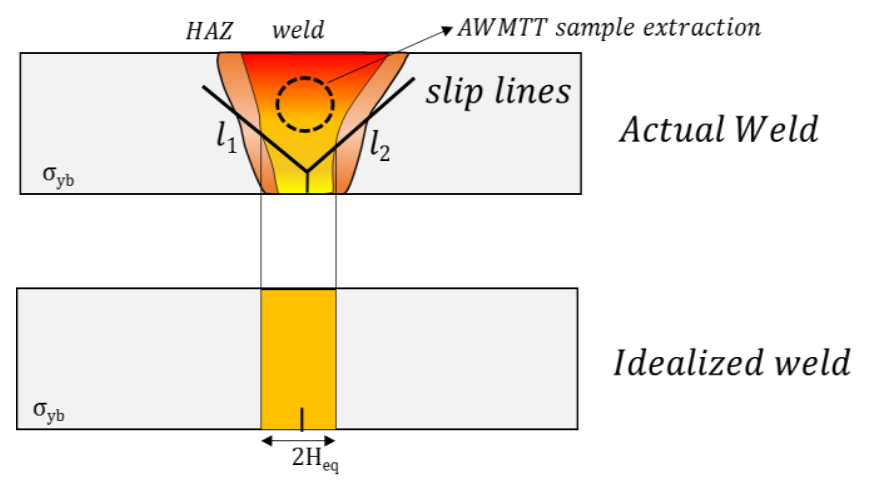

Figure 1:Procedure to idealize a weld using all weld metal tensile test and slip line assumption

The second technique used in this work to homogenize a weld was developed by Hertelé et al. [12]. Weld strength mismatch is governed by average strength properties along the slip line originating from the crack tip assumed to be in $45^{\circ}$ orientation for the case of uniaxial load perpendicular to the crack.

The procedure to simplify a weld from a hardness contour plot is as follows:

- The average hardness of the weld $\left(H V_{W M}\right)$ is calculated along the slip line originating from the crack tip (Fig 2) and the average hardness of the base is taken on the left and right side of the weld region.

$$
\begin{gathered}
H V_{W M}=\frac{l_{1}}{l_{1}+l_{2}} H V_{\text {avgleft }}^{W M}+\frac{l_{2}}{l_{1}+l_{2}} H V_{\text {avg right }}^{W M} \\
H V_{B M}=<H V_{\text {avgleft }}^{B M}, H V_{\text {avg right }}^{B M}>
\end{gathered}
$$

where $l_{(.)}$is the length of the slip line originating from the crack tip up to the HAZ/base material interface at an angle of $45^{\circ}$.

- From $H V_{W M}$ and $H V_{B M}$, yield strength $R_{p 02}$, ultimate tensile strength $R_{m}$, yield to tensile ratio $R_{p 02} / R_{m}$ and strain hardening exponent $n$ is calculated from transfer functions using AWMTT and base metal tensile tests respectively. These equations are experimentally calibrated and have been validated [13].

- The obtained material properties are assigned to the weld region (homogeneous weld)

- The equivalent length of the weld $\left(2 \mathrm{H}_{e q}\right)$ is determined to perform idealization. (Figure 2)
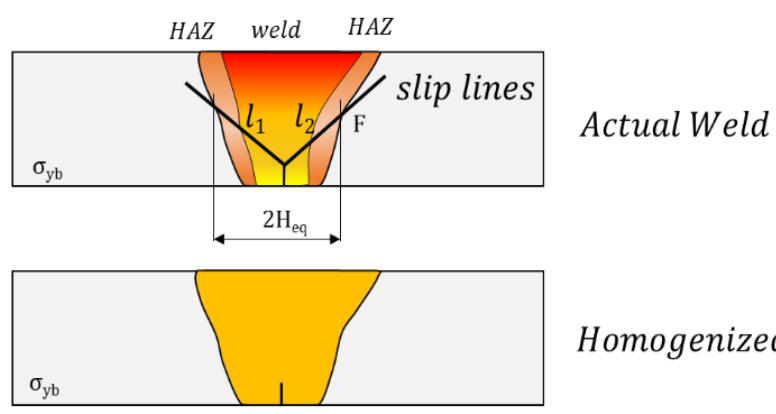

Homogenized weld

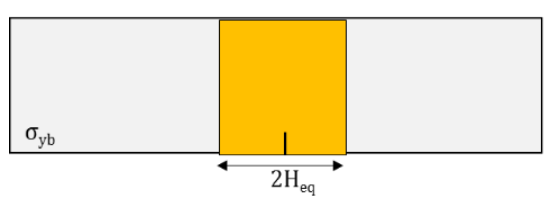

Idealized weld

Figure 2: Procedure to homogenize and idealize a weld using the concept of slip lines.

The methods used for weld simplification (including homogenization and idealization) are compared with the actual 
weld on the basis of their accuracy in predicting plastic loads through numerical simulations.

\section{Experimental techniques}

The evaluation of weld simplification schemes is performed using experimentally determined material properties for pipe girth welds. Two weld samples were extracted from a girth weld connecting 36" (914.4 $\mathrm{mm}$ ) diameter and $17.1 \mathrm{~mm}$ thick steel pipe having different degree of overmatch and welding technique (Fig. 3 - Sample A and B). The third weld sample was extracted from 48" (1219.2 mm) diameter and $19.3 \mathrm{~mm}$ (Fig 3 - Sample $C$ ). The steel grade was API 5L grade X70 (specified minimum yield strength $485 \mathrm{MPa}$ ). The pipes were shielded metal arc welded (SMAW).

$5 \mathrm{kgf}$ Vickers hardness mapping was performed and contour plots are shown in Figure 3. The root and the cap regions of the weld are also shown. The samples were chosen as they show a variable degree of heterogeneity. In sample $\mathrm{A}$ and $\mathrm{C}$, the hardness varies from $170 \mathrm{HV}$ to $290 \mathrm{HV}$ in weld region. They show a high amount of softening in HAZ and apparent variations of hardness within the weld material. Sample B has well-defined weld zone and has a higher hardness compared with other samples. HAZ softening nor hardening is evidenced. These samples will offer good understanding of the notch behavior when located in different regions of the weld. The variations in weld parameters (heat input, consumable etc.) are the reason for the softer root and a harder cap. This type of diversity in the weld facilitates a valuable study of heterogeneous behavior of a weld under loading conditions.

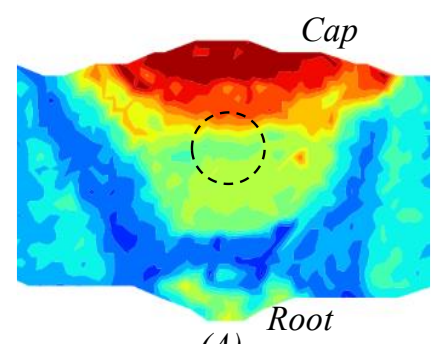

(A)

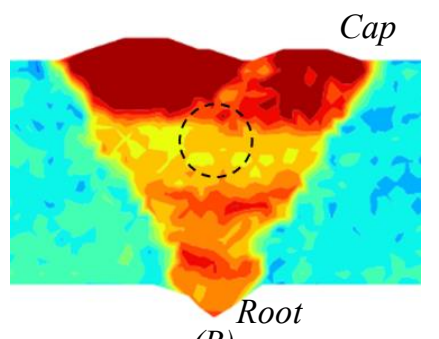

(B)
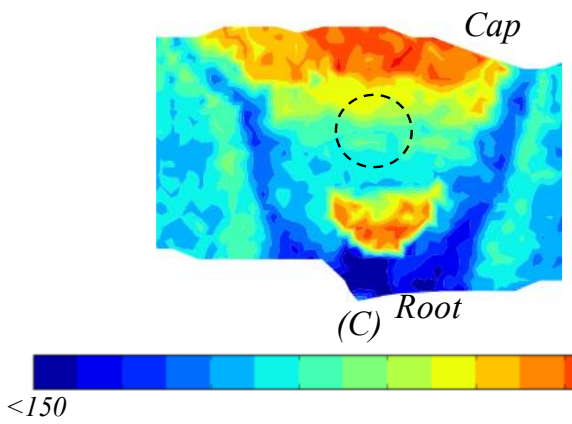

$H V$

Figure 3: Three $5 \mathrm{kgf}$ Vickers hardness contour plots of the samples (A, $B$ and $C$ ) taken from X70 steel pipe and indications of AWMTT cross section positions. The root and cap regions of weld are also shown.
All weld metal tensile test samples were extracted from $2 / 3$ distance of the inner diameter. The region is pointed out in figure 3 by black dashed circle. This choice was made based on weld geometry and ability to extract all weld sample without the presence of heat affected zone. The gauge diameter of the samples was $5 \mathrm{~mm}$. The dimensions of the sample were based on ASTM E8/E8M [14]. Figure 4 shows stress-strain curves obtained from AWMTT tests of the considered samples.

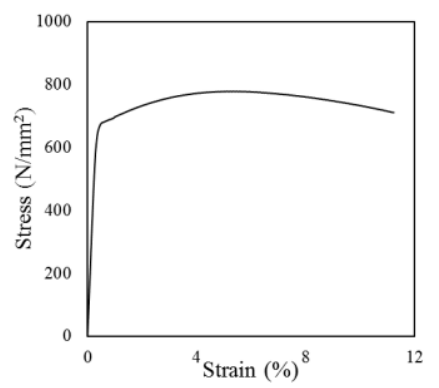

Sample A

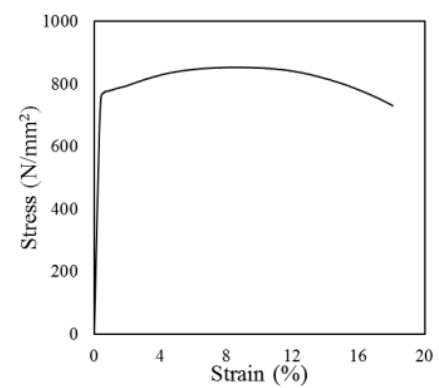

Sample B

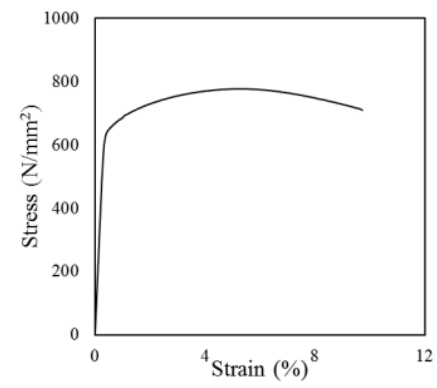

Sample C

Figure 4: Plots of stress vs. strain obtained from AWMTT of three samples.

\section{NUMERICAL FRAMEWORK}

Two weld homogenization techniques discussed in the previous section are evaluated using numerical models based on actual and idealized welds. The FE model simulates a SE(T) specimen under 2D plane strain with clamped boundary conditions. The daylight length $(L)$ of the specimen is $200 \mathrm{~mm}$ and thickness $(W)$ is $15 \mathrm{~mm}$. Three notch depths were considered for the study i.e. $a / W=0.2,0.3$ and 0.4 , with $a$ being the depth of the notch. The notch was located in the root as well as in the cap of the weld and was introduced in weld metal center. The notch tip radius $(\rho)$ was chosen to be $0.075 \mathrm{~mm}$.

These specimen configurations were modeled in Abaqus 6.11. A displacement $u / L=0.015$ was applied on one end of the specimen. The model consisted of $\sim 2200$ linear elements with a reduced integration scheme. Isotropic $J_{2}$ type plasticity obeying Ramberg-Osgood(RO) strain hardening was implemented [15]. The model details are shown in Figure 5. 


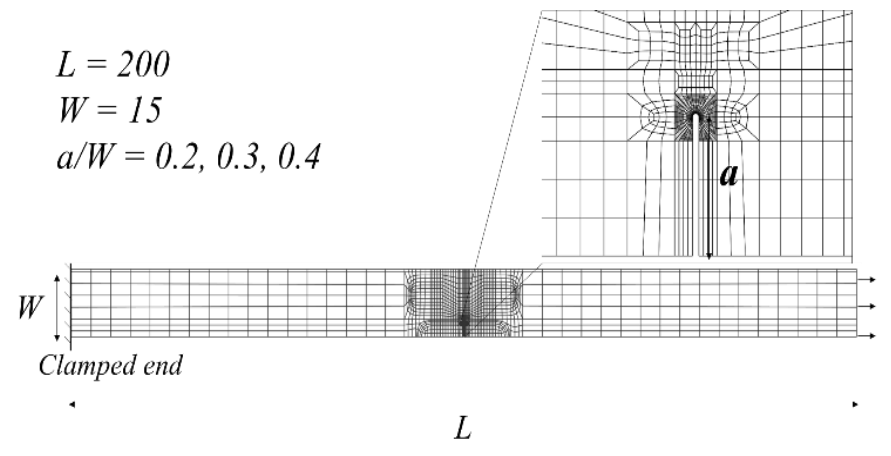

Figure 5: SE(T) finite element model showing meshing pattern, weld width and the notch

The term 'actual weld' is used for the numerical model which replicates the real local properties of a weld using the algorithm described in reference [10]. This scheme takes hardness values from HV5 map as the input, converts them to $\mathrm{RO}$ parameters and assigns them to the corresponding element. The disparity in conversion of HV5 values to RO parameters has been inspected in previous study [13]. Several standard transfer functions were analyzed and an improvised technique to determine RO parameters was put forward. Accordingly, HV5 values were converted to RO parameters using experimentally calibrated equations which uses all weld metal tensile tests. The equations are given below.

Ultimate tensile strength $R_{m}$ is calculated by,

$$
\boldsymbol{R}_{\boldsymbol{m}}=R_{m(A W M T T)} * \frac{H V}{H V_{A W M T T}}
$$

Yield strength $R_{p 02}$ is calculated by,

$$
\boldsymbol{R}_{\boldsymbol{p 0 2}}=R_{p 02(A W M T T)} * \frac{H V}{H V_{A W M T T}}
$$

The strain hardening is closely related to yield to tensile ratio according to Considère's necking criterion. Their relation has been curve-fitted into:

$$
n=2.4+2.9 \frac{R_{p 02(\text { AWMTT })} / R_{m(\text { AWMTT })}}{1-0.95 R_{\text {p02(AWMTT })} / R_{m(\text { AWMTT })}}
$$

$H V_{A W M T T}$ is the average hardness of the region where the all weld metal sample is extracted in the weld. $R_{m(A W M T T)}$ and $R_{p 02(A W M T T)}$ are the values obtained from all weld metal tensile test.

The final model of the actual weld for Fig 3(A) is shown in Figure 6.
The idealized model has two different homogeneous layers - Base and weld region. Base material is assigned with the properties obtained from $H V_{B M}$. The weld region is assigned with material properties based on the two homogenization schemes explained before. The width of the weld $\left(2 \mathrm{H}_{e q}\right)$ is calculated using hardness maps based on the technique shown in Fig. 1 and 2 .

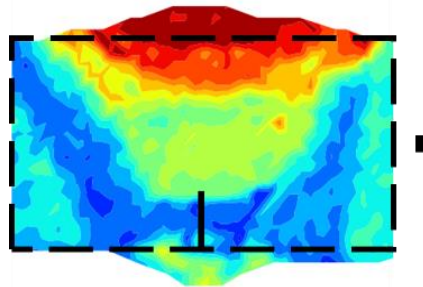

(a)

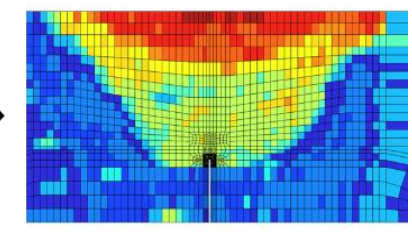

(b)

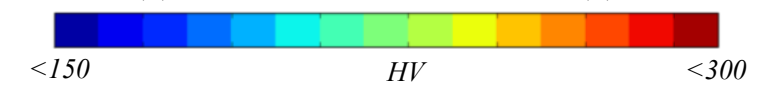

Figure 6: Numerical outcome of (a) hardness assignment to (b) individual element of finite element model.

In summary, 54 simulations have been performed covering 3 welds, $3 a / W$ ratios, 2 notch locations and 3 analyses (heterogeneous weld and two simplified welds).

In order to assess the load bearing capacity of the material before and after weld homogenization, plastic load of SE(T) sample is determined. ASME Section III [16] recommends the use of Twice Elastic Slope (TES) method to determine plastic load using Force-Displacement plot. Figure 7 demonstrates TES method.

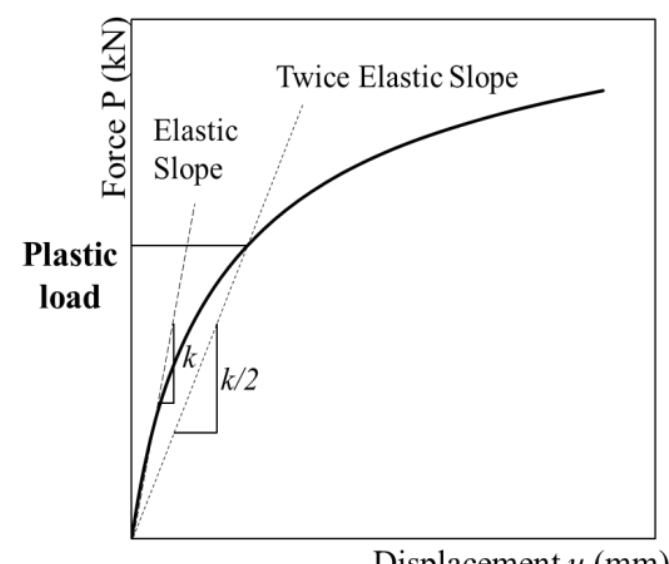

Figure 7: Plastic load estimation using twice elastic slope method

\section{RESULTS AND DISCUSSIONS}

\section{The force-displacement curve response}

Figure 8 shows $F$ - $u$ plots for different notch locations and depths for weld $\mathrm{A}$. The notch was in root and cap regions which are shown in Fig. 3. It is evident from Fig. 8 that the increase in 
depth of the notch reduces the load bearing capacity of the SE(T) specimen. Nevertheless, it is important to note the inconsistency in this trend. The variability in forces for different notch depths depends on its location in the weld and affects the plastic load of the specimen. The extent of the variability in idealized welds for similar phenomenon will be assessed.

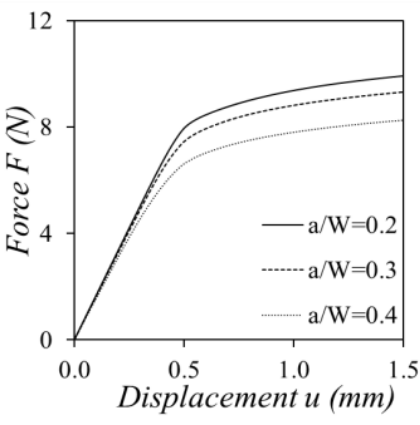

(a)

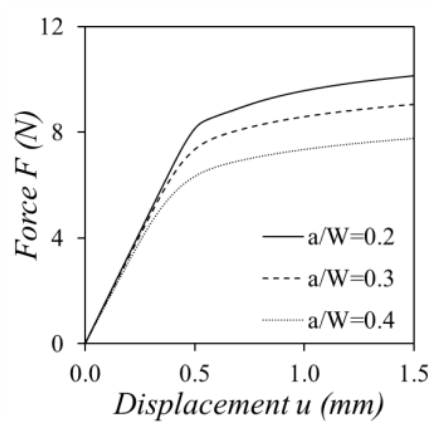

(b)
Figure 8: Comparison of F-u plots of SE(T) simulations with actual weld A for notch located in (a) root and (b) cap

\section{Validation of weld homogenization schemes}

In the first method using AWMTT results, yield strength $R_{p 02}$, ultimate tensile strength $R_{m}$, yield to tensile ratio $R_{p 02} / R_{m}$ and strain hardening exponent $n$ of the three samples (A, B and C) were obtained from all weld metal tensile tests. Table 1 summarizes the data obtained from experiments.

Table 1: Constitutive properties of weld metal obtained from all weld metal tensile tests.

\begin{tabular}{cccccc}
\hline Sample & $\begin{array}{c}\text { Average } \\
\text { Hardness }\end{array}$ & $\begin{array}{c}\text { Yield } \\
\text { Strength } \\
\left(\mathbf{N} / \mathbf{m m}^{2}\right)\end{array}$ & $\begin{array}{c}\text { Ultimate } \\
\text { tensile } \\
\text { strength } \\
\left(\boldsymbol{N} / \mathbf{m m}^{2}\right)\end{array}$ & $\begin{array}{c}\text { Yield } \\
\text { to } \\
\text { tensile } \\
\text { ratio }\end{array}$ & $\begin{array}{c}\text { Strain } \\
\text { hardening } \\
\text { exponent }\end{array}$ \\
\hline$A$ & 240.23 & 674.66 & 777.8 & 0.87 & 16.96 \\
$B$ & 260.62 & 752.94 & 850.3 & 0.89 & 18.61 \\
$C$ & 217.79 & 621.08 & 731.6 & 0.85 & 15.27
\end{tabular}

The weld properties were assigned to the finite element model based on the values from Table 1 and simulations were performed. The thickness of the weld $2 H_{e q}$ was different for each specimen as it was determined based on the method shown in Figure 1. Plastic loads obtained from TES method suggest an error average of $\sim 8 \%$ between the maximum and minimum errors of homogenized weld compared with actual weld among the chosen samples and configurations. The results have an error range varying from $0.9 \%$ to $-15 \%$. The error was based on the ratio of plastic load obtained from actual and idealized weld. A positive error suggests a conservative result and a negative error shows an overestimation of plastic load compared to the actual weld. Figure 9 shows the comparison. The variability of error was quantified using standard deviation and was found to be $\sim 4.5 \%$. In all cases, the idealization process leads to over estimation of plastic loads.

The second method, which considers the slip lines originating from the crack tip in order to obtain constitutive properties, includes more parameters in order to simplify a weld. As per this technique (as explained in Materials and Methods section), average hardness calculated was based on notch depth and location. The results are given in Table 2 . The variability in hardness values depending on the location and depth of the notch can be seen. Another observation from Table 2 is that hardness increases with the increase in notch depth in the root while it shows a decreasing trend at the cap. This is due to the fact of having a harder region in the cap and a comparatively softer region in the root. Slip line method takes varying hardness into the account while AWMTT is based on constant hardness. The values of hardness can be seen in Table 1 and 2 .

The hardness values from Table 2 were used to obtain material parameters - yield strength $R_{p 02}$, ultimate tensile strength $R_{m}$, yield to tensile ratio $R_{p 02} / R_{m}$ and strain hardening exponent $n$ was calculated using the Equations 1-3. With material parameters in hand, the $\mathrm{SE}(\mathrm{T})$ simulations for the homogenized weld was performed. The average error in plastic load observed for the considered specimens and configurations in this method was $\sim 2 \%$. The variation of results ranges from $8 \%$ to $-10 \%$. The standard deviation of errors was $\sim 6 \%$. This technique improved the average error from previous AWMTT technique owing to its ability to involve more parameters. The results comparing the plastic loads of actual weld and idealized welds using two methods are shown in Figure 9. In case of Sample A, the plastic loads were underestimated leading to conservative results and samples $\mathrm{B}$ and $\mathrm{C}$ had errors which are less than the AWMTT technique of homogenization though the plastic loads are overestimated.

Table 2: Results of average hardness taken along the slip lines originating from the crack tip in $S E(T)$ samples

\begin{tabular}{ccccc}
\hline $\begin{array}{c}\text { Notch } \\
\text { Depth }\end{array}$ & $\begin{array}{c}\text { Notch } \\
\text { Location }\end{array}$ & \multicolumn{3}{c}{ Hardness $\left(\mathrm{HV}_{\text {avg }}\right)$ of weld } \\
$(\boldsymbol{a} / \boldsymbol{W})$ & & Sample A & Sample B & Sample C \\
\hline 0.2 & & 238.92 & 263.32 & 219.78 \\
0.3 & Root & 240.46 & 272.62 & 226.42 \\
0.4 & & 247.67 & 276.66 & 230.77 \\
& & & & \\
0.2 & & 215.49 & 259.65 & 208.87 \\
0.3 & Cap & 211.96 & 256.4 & 202.42 \\
0.4 & & 209.97 & 258.81 & 198.99 \\
\hline
\end{tabular}

Three important observations can be made from this plot. Firstly, there is a significant variation of plastic load values 
which reconfirms the effect of weld heterogeneity on load bearing capacity as mentioned by researchers, codes and standards $[1,6,7]$.

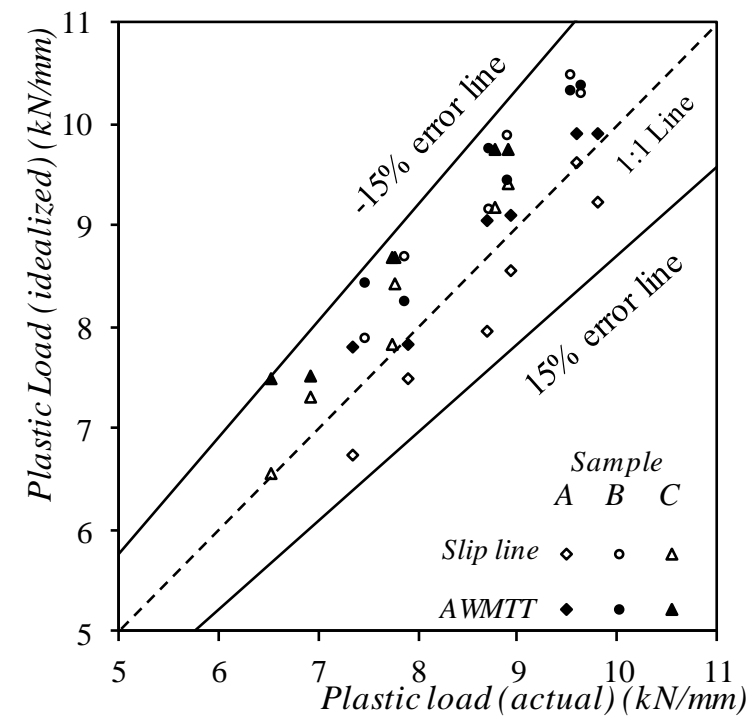

Figure 9: Plastic load comparison between actual and idealized weld

Secondly, the difference in plastic load between two schemes of homogenization has high variations. In certain cases, there is a noticeable difference $(\sim 8 \%)$. But most of the cases it is less than $2 \%$. Third and most important observation regarding the safety of the welded structure is that the plastic load suggested by homogenization schemes are higher than the actual plastic loads (except Sample A idealization using slip line method). This means that the actual structure reaches its plasticity limit sooner that the predicted plastic load of a simplified weld. Further validation can substantiate these observations.

\section{Scrutiny of heterogeneity effects on weld simplification}

In this subsection, a detailed analysis of the plastic load variations is made considering equivalent plastic strains (PEEQ) and slip lines originating from the crack tip. The investigation of plastic loads of actual and idealized welds shows the variability of currently used techniques to analyze a weld defect. The variations observed in the plastic loads deserves consideration in ECA methods. In order to understand these variations, a detailed analysis based on slip lines observed in numerical simulations is conducted.

Researchers [12,17-20] typically assume that the slip line pattern obtained from a notched weld is a straight line, mostly $45^{\circ}$. This consideration was based on a homogeneous body or a mismatched weld. The mismatch always meant to be strength variation between two or three regions of the weld. But an inconsistent strength variation inside the weld region is not considered in this assessment. The observations regarding the effects of strength variations on equivalent plastic strain (PEEQ) are made in this numerical study. Figure 10 shows strain concentration bands originating from the notch tip in a homogeneous weld. From these, "Slip lines" have been derived as a trajectory of maximum PEEQ towards root/cap. The presented configuration in Fig. 10 is a homogenized specimen of sample A having a notch depth $\mathrm{a} / \mathrm{W}=0.3$. Similar slip line patterns were observed in idealized specimens (using both homogenization schemes) of three samples. The white dashed and solid lines are drawn to show the pattern of assumed and obtained slip lines for the convenience of the reader.

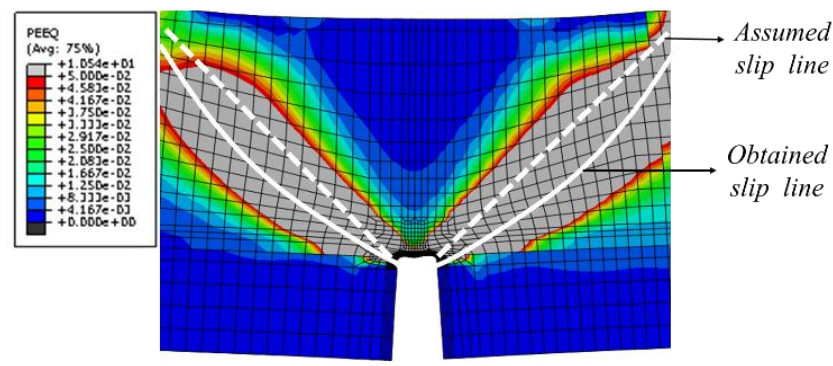

Figure 10: Strain concentration bands during simulation of deformation in a simplified weld

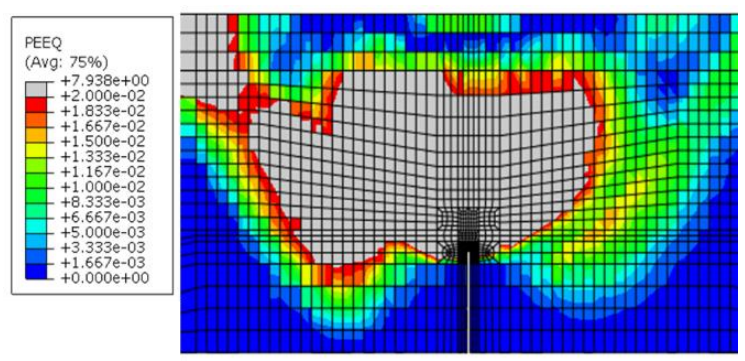

Contour at un-deformed state

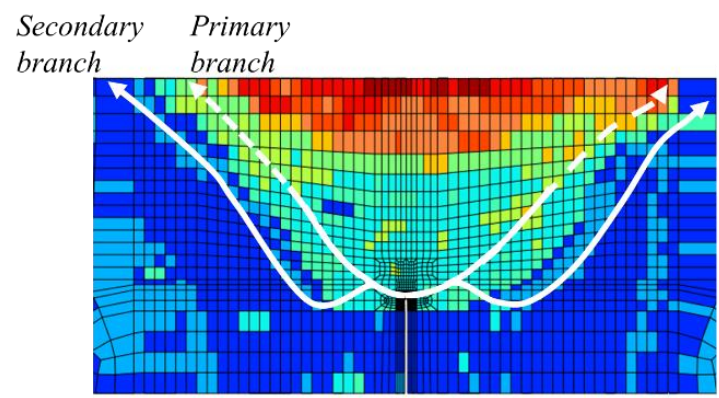

Figure 11: Non uniform stress concentration bands observed in actual weld simulations for a notch located in the root (for Sample A). 
The assumption of straight $45^{\circ}$ slip lines becomes doubtful when considering actual welds. The high strain regions in actual and homogenized welds are incomparable. Two examples from different set of simulations chosen to analyze the slip lines in actual welds. (i) notch located in root and $\mathrm{a} / \mathrm{W}=0.3$ of sample $\mathrm{A}$ (fig. 11 illustrates the case of notch tip located in softer region) and (ii) notch located in cap and a/W=0.2 of Sample B (fig. 12 illustrates the case of notch tip located in harder region). It is important to note that the Figures 10,11 and 12 were obtained at the same intervals of deformation. PEEQ concentration bands of case (i) can be seen in Figure 11.

The strain concentration bands arising from the notch tip tend to flow to the region having low hardness. This means that the harder region resists deformation creating a non-straight slip front. The bands merged inside the material at the fusion line on the left side and flow to the base material on the right side.

As deformation is applied, a secondary branch of slip lines arises in low strength material. Referring to fig. 3(A), on left hand side and the right hand side, if can be observed that there is a sudden transition from hard weld metal to a soft HAZ. This transition affects the angle of flow as the deformation tends to be higher at HAZ. This invalidates the assumption of $45^{\circ}$ slip line homogenization.

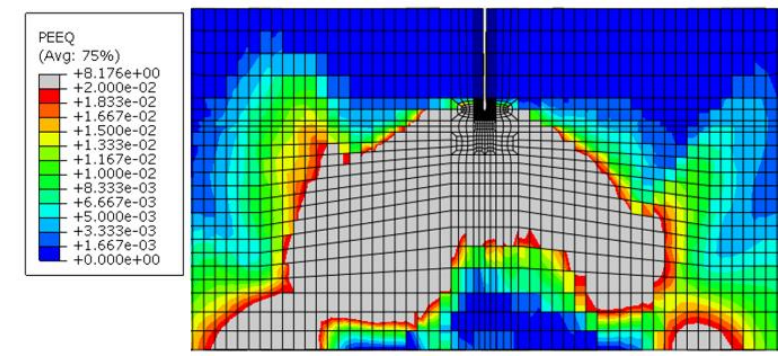

Contour at un-deformed state

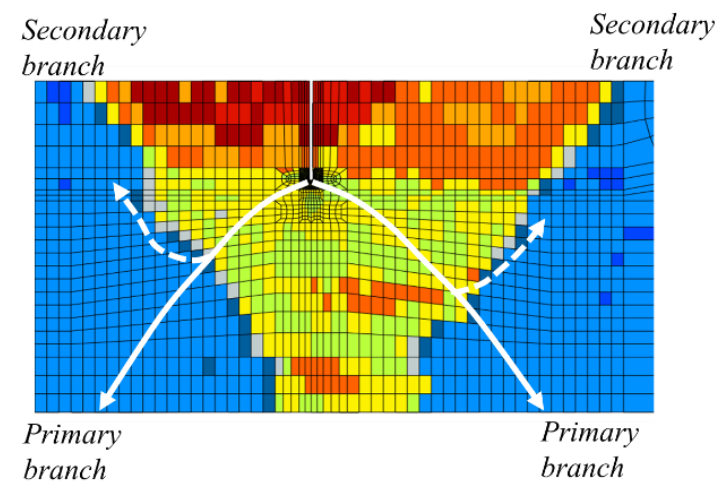

Figure 12: Non uniform stress concentration bands observed in actual weld simulations for a notch located in cap (Sample B).

By observing the strain concentrations from the notch located in cap of sample B of case (ii) (fig. 12), the region of the notch resists deformation and hence slip line flow in upward direction, showing a uniform slip line front. The primary slip line flows towards the root of the weld and the secondary slip line which begins in the region of fusion line flows towards the cap of the weld. At higher deformation, slip line run parallel to the fusion line. This can be observed from Fig. 11 and Fig. 12.

Similar slip line bands were obtained in other actual welds simulations and are confirmed by experimental results [21]. This shows that the prediction of slip lines in complex welds is challenging. But, if weld homogenization techniques are updated to address the limitations mentioned in this paper, it will be possible to improve safety and integrity of welded structures.

\section{CONCLUSIONS}

In this paper, two weld simplification techniques have been analyzed involving homogenization and geometry idealization methods. By determining plastic load using Twice Elastic slope (TES) method, a comparison was made between the structural responses of actual welds and their homogenized equivalents. Numerical simulations were performed on three weld samples taking input from hardness maps and all weld tensile tests.

The two techniques of homogenization, one using all weld tensile test data and the other using slip line concept proved to be competent techniques to simplify a weld based on error analysis. Nevertheless, due to the existence of weld heterogeneity, there is variability of plastic loads from one weld to another showing an error -10 to $15 \%$ when compared with the actual welds. An average error for the considered samples and configurations using all weld data showed $\sim 8 \%$ while the slip line assumptions showed $\sim 2 \%$. The variations were higher in slip line method than in AWMTT method. AWMTT method consistently overestimated the load bearing capacity of the welds and slip line technique showed few conservative results. In depth scrutiny showed that the pattern of slip lines is inconsistent in actual welds. The assumption of $45^{\circ}$ slip line formation in a weld is not accurate and further research is to be performed to predict slip lines in heterogeneous welds. It is expected that an accurate prediction of slip line trajectory will allow for more efficient weld homogenization.

\section{ACKNOWLEDGMENTS}

The authors would like to acknowledge FWO Vlaanderen (Research Foundation - Flanders, research grant nr. G.0609.15N) for the support provided during this research. The research leading to the experimental results has received funding from the European Union's Research Fund for Coal and Steel (RFCS) research programme under grant agreement no. RFSRCT-2013-00025.

\section{REFERENCES}

[1] U. Zerbst et al., "Review on fracture and crack propagation in weldments - A fracture mechanics perspective," Eng. Fract. Mech., vol. 132, pp. 200-276, Dec. 2014. 
[2] K.-H. Schwalbe and M. Koçak, Mis-Matching of Welds, ESIS (2nd edn)., vol. 17. London: Mechanical Engineering Publications, 1994.

[3] K.-H. Schwalbe and M. Koçak, Second International Symposium on Mis-Matching of Interfaces and Welds. Geesthacht: GKSS Research Center Geesthacht, 1997.

[4] K.-H. Schwalbe, Y. J. Kim, S. Hao, A. Cornec, and M. Koçak, "EFAM ETM-MM 96-the ETM Method for assessing the significance of crack-like defects in joints with mechanical heterogeneity (strength mismatch)," 1997.

[5] "BS 7910,(2005)." Guide to methods for assessing the acceptability of flaws in metallic structures"," Br. Stand. Inst. Lond., 2007.

[6] M. Koçak, S. Webster, J. J. Janosch, R. A. Ainsworth, and R. Koers, FITNET Fitness-for-service, vol. I. GKSS Research Center Geesthacht, 2008.

[7] "R6 Revision 4: Assessment of the Integrity of Structures Containing Defects," Br. Energy Glos. UK, 2000.

[8] E. L. Stevens, J. Toman, A. C. To, and M. Chmielus, "Variation of hardness, microstructure, and Laves phase distribution in direct laser deposited alloy 718 cuboids," Mater. Des.

[9] B. Malard, F. De Geuser, and A. Deschamps, "Microstructure distribution in an AA2050 T34 friction stir weld and its evolution during post-welding heat treatment," Acta Mater, vol. 101, pp. 90-100, Dec. 2015.

[10] S. Hertelé, N. O'Dowd, K. Van Minnebruggen, M. Verstraete, and W. De Waele, "Fracture mechanics analysis of heterogeneous welds: Numerical case studies involving experimental heterogeneity patterns," Eng. Fail. Anal., vol. 58, pp. 336-350, 2015.

[11] M. Naderi, A. Saeed-Akbari, and W. Bleck, "Quantitative and qualitative investigation of the heterogeneous microstructures using surface hardness mapping and dilatation data," Mater. Lett., vol. 62, no. 6-7, pp. 11321135, Mar. 2008.

[12] S. Hertelé, W. De Waele, M. Verstraete, R. Denys, and N. O'Dowd, "J-integral analysis of heterogeneous mismatched girth welds in clamped single-edge notched tension specimens," Int. J. Press. Vessels Pip., vol. 119, pp. 95-107, Jul. 2014.

[13] S. Naib, K. Van Minnebruggen, W. De Waele, and S. Hertelé, "Sensitivity study of crack driving force predictions in heterogeneous welds using Vickers hardness maps," in NAFEMS India Conference, 2016, p. 77.

[14] "ASTM E8/E8M: Standard Test Methods for Tension Testing of Metallic Materials," 100 Barr Harbour Drive PO Box C-700 West Conshohocken PA. 19428-2959, United States: ASTM International (ASTM).

[15] W. Ramberg and W. R. Osgood, "Description of stressstrain curves by three parameters," NACA-TN-902, 1943.

[16] ASME - STANDARDS - BPVC Section III-Rules for Construction of Nuclear Facility Components-Division 1Subsection NF-Supports. ASME, 2017.

[17] I. A. Khan, V. Bhasin, J. Chattopadhyay, and A. K. Ghosh, "On the equivalence of slip-line fields and work principles for rigid-plastic body in plane strain," Int. J. Solids Struct., vol. 45, no. 25-26, pp. 6416-6435, Dec. 2008.

[18] J. Joch, R. A. Ainsworth, and T. H. Hyde, "Limit Load and J-Estimates for Idealised Problems of Deeply Cracked Welded Joints in Plane-Strain Bending and Tension," Fatigue Fract. Eng. Mater. Struct., vol. 16, no. 10, pp. 1061-1079, Oct. 1993.

[19] Y.-J. Kim, F. A. McClintock, and D. M. Parks, "Yield Locus in Deep, Single-Face-Cracked Specimens Under Combined Bending and Tension," J. Appl. Mech., vol. 63, no. 4, pp. 1045-1047, Dec. 1996.

[20] S. Hao, A. Cornec, and K.-H. Schwalbe, "Plastic stressstrain fields and limit loads of a plane strain cracked tensile panel with a mismatched welded joint," Int. J. Solids Struct., vol. 34, no. 3, pp. 297-326, Jan. 1997.

[21] S. Hertelé, F. Van Gerven, S. Naib, N. Gubeljak, and W. De Waele, "Experimental and numerical slip line analysis of welded single-edge notched tension specimens," Procedia Struct. Integr., vol. 2, pp. 1763-1770, 2016. 